\title{
INVESTIGATION OF HEAVY METAL CONTAMINATION IN THE GROUNDWATER RESOURCES, OSHTORINAN, SOUTHWEST IRAN
}

\author{
CHITSAZAN, M. - MIRZAVAND, G. R. ${ }^{*}$-SAKI, A. \\ Department of Geology, Faculty of Earth Sciences, Shahid Chamran University of Ahvaz, \\ Ahvaz, 65355-141, Iran \\ (phone: +98-61-33333710; fax: +98-61-333331059) \\ *Corresponding author \\ e-mail: mirzavand1088@gmail.com \\ (phone:+98-91-66417396; fax +98-61-42620800) \\ (Received $13^{\text {th }}$ Sep 2016; accepted $9^{\text {th }}$ Jan 2017)
}

\begin{abstract}
For the first time, a comprehensive groundwater heavy metal and trace element study was conducted in the Oshtorinan plain situated in the north corner of Boroujerd basin located between the two important structural zones, Sanandaj-Sirjan zone in the east and Zagros in the west, aiming to investigate the impacts of natural weathering of minerals, industrial and agricultural activities on distributions of these elements. Groundwater samples were collected including ten wells, five Qanats and one spring in different seasons, and analyzed for heavy metal and trace element values using inductively coupled plasma mass spectrophotometer (ICP-MASS) and their levels compared with WHO specified maximum contaminant level. The levels of heavy metals under study in water used for drinking purpose are below the maximum allowable limits recommended by $\mathrm{WHO}$ except for $\mathrm{Fe}, \mathrm{Mg}, \mathrm{Pb}, \mathrm{Sr}$, and $\mathrm{V}$.The levels of $\mathrm{Pb}$, $\mathrm{B}$ and $\mathrm{Fe}$ in groundwater in the area understudy increase from east and west to center.It is found that elevated levels of the strontium concentration $(\mathrm{Sr}$ ) in groundwater were considered to be mainly the result of natural processes such as the weathering of minerals such as feldspars in granites and Granodiorites. Wells diesel engines are a probable source of contamination in the area, because in the region about 88 wells of total 144 wells have been excavated are diesel engines. Alloy steel industries, especially in the aquifer from the north entrance that release their effluent on ground surface Could be a potential source of contaminants such as heavy and trace metals and threat the environment and groundwater.
\end{abstract}

Keywords: groundwater quality, agricultural acivities, Sanandaj-Sirjan, rock-water interaction, trace element

\section{Introduction}

Rapid industrialization process coupled with spiraling growth in global population has been instrumental in increased agricultural production. These have had the legacies of pollution of various kinds that has reportedly undermined the integrity of environment and eco-system. This has moreover, brought about an increasing pollution index in natural environments, such as water bodies, soil structures, air, etc. (Thibodeaux, 1996; Dawson and Macklin, 1998; Murena, 2004; Hassanzadeh et al., 2011; Wauchope, 1978). Groundwater aquifers and water bodies are among the most important sources which are under frequent threat of pollution and contamination (Momodu and Anyakora, 2010; Vodela et al., 1997). Heavy metals are said to play a major role in degrading these vital renewable resources that has attracted the attention of various research investigations. One of the major attributes of these contaminants is the severity of their toxicity even at low concentrations (Marcovecchio et al., 2007; Botté et al., 2007). 
Heavy metals are among the chemical elements with atomic weights ranging between 63.546 and 200.590 and a specific gravity greater than 4.0 i.e. at least 5 times that of water. Their existence in water can be in the form of colloidal, particulate and dissolved phases (Greenwood and Earnshaw, 2012). with their occurrence in water bodies being either of natural origin (e.g. eroded minerals within sediments, leaching of ore deposits and volcanism extruded products) or of anthropogenic origin (i.e. solid waste disposal, industrial or domestic effluents, harbor channel dredging) (Marcovecchio et al., 2007).

Increase in anthropogenic growth of the heavy metals, has called for more investigation of the effects of those pollutants in the environment (Marengo et al., 2006). Sources of heavy metals in water bodies consist of natural sources including eroded minerals within sediments, and leaching of ore deposits. Heavy metals in nature are not usually significantly hazardous to the environment and human health. Having said so, a limited amount of these heavy metals at low concentrations are necessary as catalysts for enzyme activities in human body $(\mathrm{Co}, \mathrm{Cu}, \mathrm{Fe}, \mathrm{Mn}$ and others). Under the circumstances where the levels of these metals exceed the normal ranges, they can affect the physiological functioning of the body organs due to the toxicity they bond to bring about in the human body (Pirsaheb et al., 2013).

Oshtorinan plain within the north of Boroujerd basin with an area spanning approximately $389 \mathrm{~km} 2$ is bounded by the Eastern and Western different structural zones. The chemical quality of these ground water sources are affected by the characteristics of the media through which the water passes on its way to the ground water zone of saturation (Adeyemi et al., 2007). Thus, the heavy metals discharged through industrial effluents, traffic, municipal wastes, hazardous waste sites as well as unsystematic application of agri-inputs and accidental oil spillages from oil tankers. All of these have the potential in gradual rise in contamination of groundwate aquifers.

Groundwater is considered as the major source of water supply for domestic, agricultural and industrial sectors. It can be in various forms of which the wells, springs and Qanats are the principal examples. Groundwater resources of Oshtorinan are reportedly under serious threats by contamination from municipal sewage, industrial effluents and excessive application of agri-inputs. Despite the seriousness and gravity of the potential pollution hazards that these post-modern activities can bring about, no proportional investigation of the scale it deserves have been undertaken. This is certainly the case for the Oshtorinan water basin baring a summary report on the existence of major ions in the groundwater (Asarab, 2012). Based on such a background, there is an urgent need to undertake a systematic investigation of the nature of the pollutions and the manner in which they threaten the integrity of the environment and livelihood of those whose survival depends on these vital renewable sources.

The paper aims to achieve the following objectives. (i) to determine the heavy metals level in water samples using ICP_MS. (ii) to examine the spatial distribution of heavy metal level in the groundwater. (iii) To identify the potential pollutant sources. The methodology involves using a correlation between metals as a means of identifying the possible sources of metal pollutants in the groundwater. The study is undertaken with an objective of identifying the manners in which to enhance the integrity of these water bodies through systematic environmental monitoring, effective remediation, and viable planning to ensure sustainable groundwater abstraction in this strategically important region in Iran. 


\section{Materials and methods}

\section{Study area}

Oshtorinan plain, is one of the small sub basin in the Lorestan province of Iran that situated in the north corner of Boroujerd basin (Fig. 1). The area is located between the two important structural zones, Sanandaj-Sirjan zone in the east and Zagros structure as the west border that can be affected differently by them. It is situated between $33^{\circ} 56^{\prime}-$ $34^{\circ} 03^{\prime} \mathrm{N}$ and $48^{\circ} 56^{\prime}-49^{\circ} 07^{\prime} \mathrm{E}$ and covers $389 \mathrm{~km} 2$ with about $1600 \mathrm{~m}$ above the sea level. Average annual rainfall of the study area is around $464 \mathrm{~mm}$ that only fifteen percent of it is recharging to groundwater.

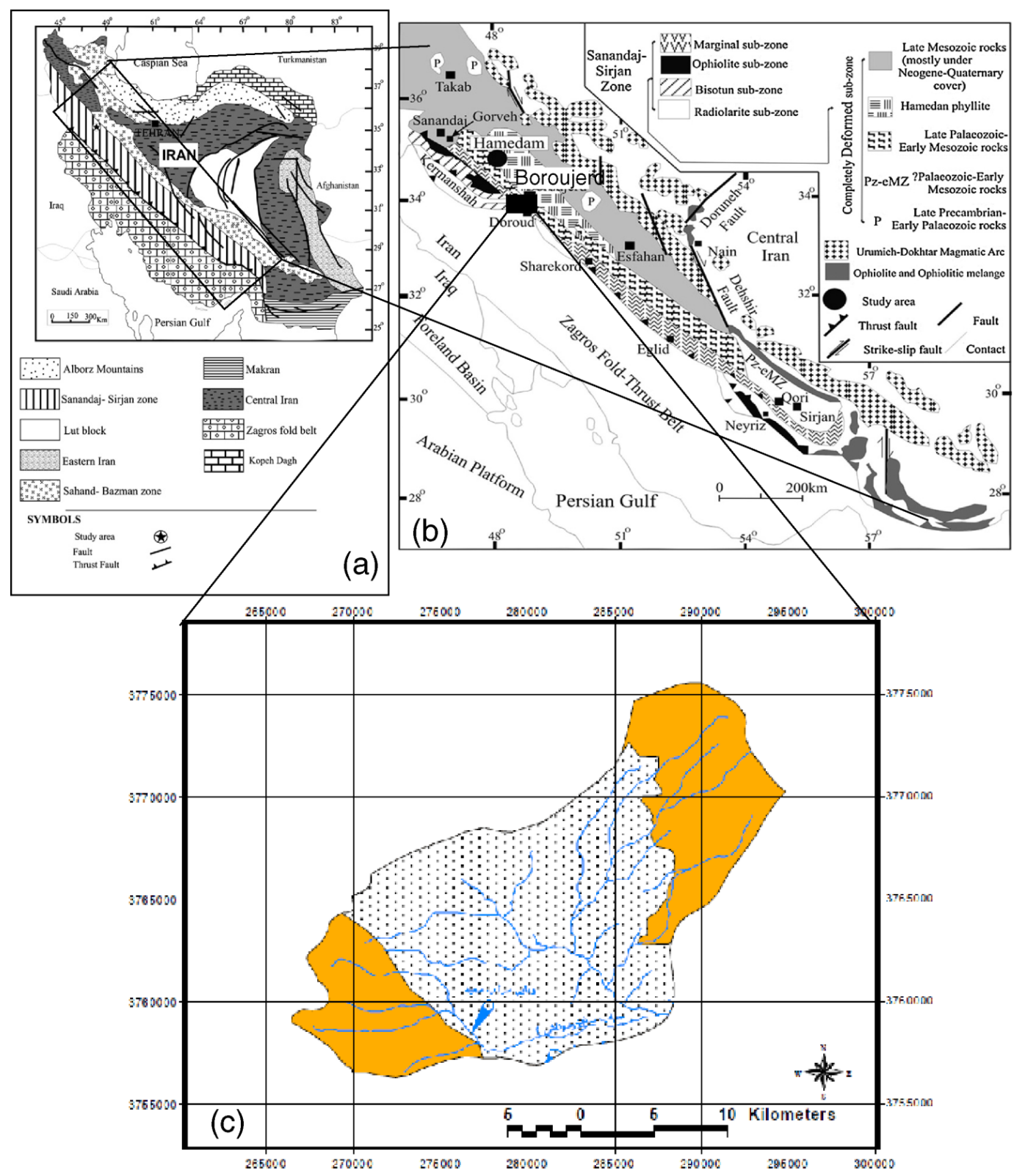

Figure 1.a) Generalized geological map of Iran (modified from (Khalaji et al., 2007) showing major lithostructral zones. b) Schematic geotectonic sketch of western Iran (modified from

(Mohajjel et al., 2003) showing location of the Oshtorinan. c) Oshtorinan plain 
Geology

The study area can be divided into two parts with significantly different modes of development. High unconformity of second and third era has been observed in the central Iran but none of them is seen in the Zagros. In the southwest heights, rocks are mainly composed of limestone, marl, sandstone and conglomerate with Miocene age. In the North East and East, Jurassic and Cretaceous igneous rocks consist of Granite and Granodiorite and also metamorphic rocks such as Schist, Gneiss and Hornfelse have existed. Limestone formations outcrop near Zagros with high developed cracks due to the many large springs have abundant yield, While the outcrop of igneous and metamorphic rocks of central Iran have the lower springs discharge. Sanandaj-Sirjan metamorphic area has hummocky landscape, but sometimes more intrusive rocks embedded into the rocks caused the rough morphology. Southwest and western Zagros Range Configuration is a folded mountain belt with highest heights.

Fig. 2 is a geological map of the rocks type distribution of Oshtorinan basin(Hajmollali et al., 1991). Eighteen lithological units were mapped that are, recent deposits, Hornfelse, Clay flats, Granite Granodiorite, limestone, limestone, marble, marl, sandstone, conglomerate, dotted schist, dolomite, philite, metamorphed sandstone, colored mélange, new and old terraces.
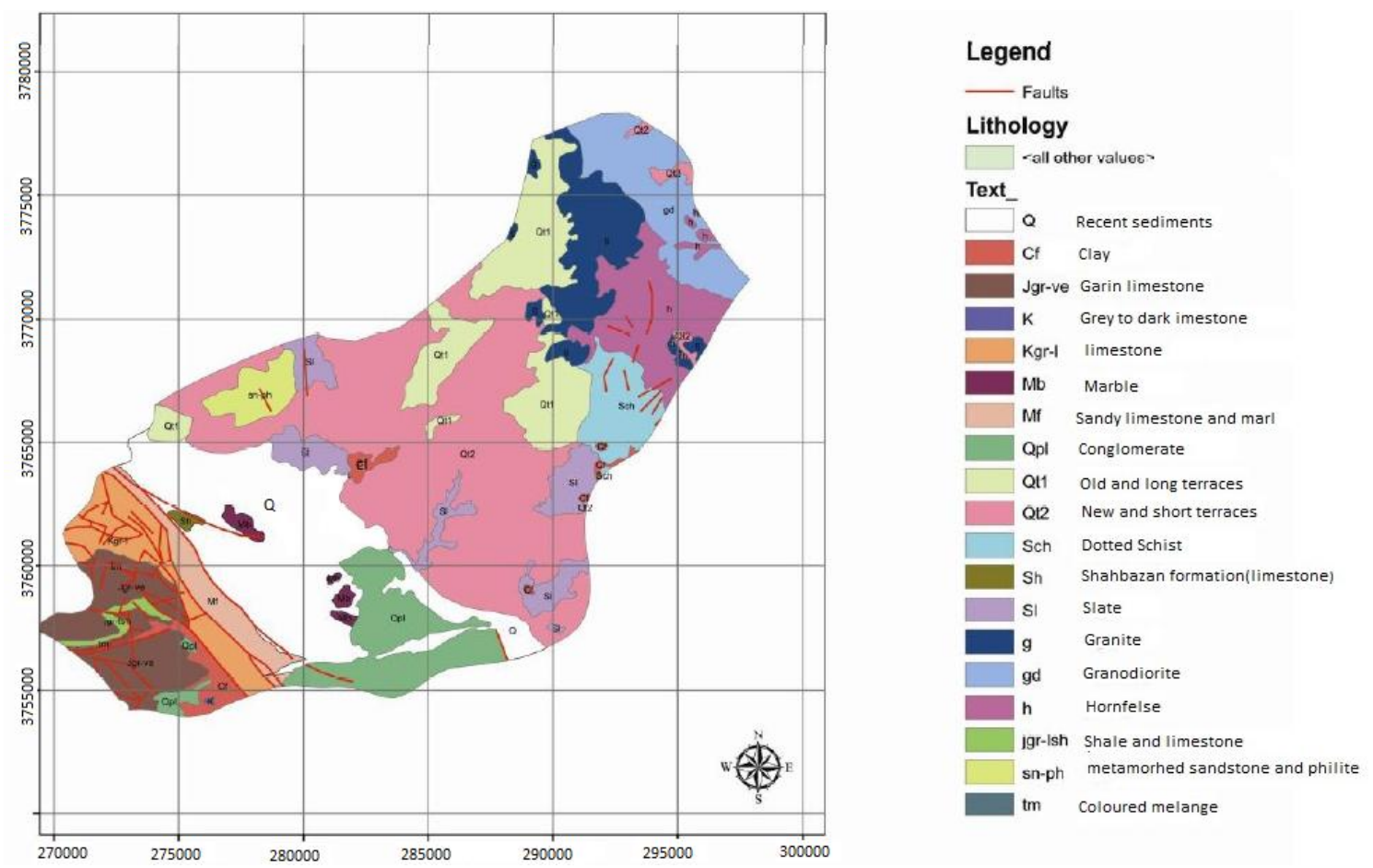

Figure 2. Geological map of the Oshtorinan plain

\section{Sampling}

In their study, a total of 32 samples were obtained from various resources (13 wells, two Qanats and one spring) from Oshtorinan plain to provide good spatial coverage in the studied area. During sampling all the precautions were taken according the standard 
guidelines, to avoid any possible contamination. Sample batches were regularly interspersed with standards and blanks, and all data were corrected for instrument drift. A three-point calibration curve was constructed for each element. The results of three replicate analyses indicated that the precision of cation measurements was generally better than $5 \%$.

The latitude and longitude values for all locations are introduced in (Table 1). The groundwater samples were collected from the outlets of the wells after flushing water for $10-15 \mathrm{~min}$ in order to remove the stagnant water. Tight-capped high quality polyethylene bottles (HDPE) were used for sample storage. Before use, the bottles were washed by distilled deionized water. Samples were filtered through $0.45 \mathrm{~mm}$ cellulose filter paper. To prevent precipitation of metals and biological growth, few drops of concentrated nitric acid were added to samples to obtain pH around 2 (Eaton et al., 1995). Thereafter, samples were immediately transported to the laboratory in iceboxes and stored at $4^{\circ} \mathrm{C}$ up to analysis.

At field, the $\mathrm{pH}$, Eh, temperature, electrical conductivity (EC), and dissolved oxygen (DO) of water samples were measured by using a portable multimeter (Hach- HQ40d, USA) by portable colorimeter (Hach-890) (Table 1). Acidified aliquots were analyzed for heavy metals and trace elements by inductively coupled plasma mass spectrometry (ICP-MS, HP_4500) except for boron (B) which was analyzed by inductively coupled plasma atomic emission spectrometry (ICPAES). Unacidified aliquot was analyzed for major anions by Ion Chromatography.

The GIS mapping technique was adopted to demonstrate the spatial distribution of major ions and heavy metals concentrations in the groundwater by using ArcGIS (version 9.3). Descriptive statistics and correlation coefficients among all the parameters were calculated using software SPSS 16 (Table 2).

Table 1. Parameters measured at field

\begin{tabular}{r|r|r|c|c|r|r|r|r|r|r}
\hline No & Location & Source & X & Y & Z & pH & Eh & $\mathbf{T}^{\text {oc }}$ & EC & Do \\
\hline Q1 & Darehgarm & Qanat & 288134 & 3765103 & 1844 & 8.11 & -27.2 & 14.9 & 557 & 7.82 \\
\hline Q2 & Deh Torkan & Qanat & 289424 & 3766506 & 1925 & 8.14 & -24.5 & 14.7 & 535 & 7.85 \\
\hline Q3 & Davaei & Qanat & 289488 & 3768166 & 1972 & 8.16 & -32.4 & 13.4 & 480 & 7.84 \\
\hline Q4 & Ghorchali & Qanat & 290552 & 3769731 & 2074 & 8.19 & -37.3 & 14.5 & 269 & 7.55 \\
\hline Q5 & Ahmadi & Qanat & 291382 & 3768334 & 1981 & 8.12 & -29.2 & 15.1 & 381 & 7.45 \\
\hline W1 & Bayatan & Well & 289749 & 3774370 & 2164 & 7.66 & -29 & 14.7 & 572 & 6.82 \\
\hline \multirow{2}{*}{ W2 } & Deh Yousef & Well & 283840 & 3772978 & 1914 & 7.88 & -32.1 & 16.2 & 402 & 7.42 \\
& Ali 1 & & & & & & & & & \\
\hline W3 & Deh yousef & Well & 285792 & 3773387 & 1969 & 7.81 & -27.1 & 15.9 & 426 & 7.42 \\
\hline W4 & Crashing & Well & 283266 & 3772564 & 1922 & 7.84 & -39.7 & 18.7 & 413 & 7.54 \\
\hline W5 & Dehriz & Well & 281887 & 3773040 & 1906 & 7.99 & 47.6 & 17.3 & 511 & 7.58 \\
\hline W6 & Reza abad & Well & 280051 & 3771338 & 1862 & 7.7 & -27.7 & 18.3 & 629 & 7.51 \\
\hline W7 & Tudehzan & Well & 281865 & 3761840 & 1729 & 7.62 & -29.3 & 19.7 & 1085 & 7.26 \\
\hline Q6 & Qayed Taher & Qanat & 276201 & 3764760 & 1807 & 7.34 & -12.1 & 14.5 & 350 & 8.4 \\
\hline Q7 & Charboreh & Well & 279011 & 3763455 & 1749 & 7.3 & -8.4 & 14.9 & 595 & 9.93 \\
\hline W8 & Bondizeh & Well & 278444 & 3759497 & 1768 & 7.82 & -38.2 & 18.7 & 424 & 6.33 \\
\hline S1 & Kartoil & Spring & 275890 & 3760589 & 1838 & 8 & -78 & 11.5 & 241 & 8.8 \\
\hline
\end{tabular}


Table 2. correlation coefficients of heavy metal and trace elemnts in groundwater

\begin{tabular}{c|c|c|c|c|c|c|c|c|c}
\hline & $\mathbf{p b}$ & $\mathbf{M g}$ & $\mathbf{F e}$ & $\mathbf{s r}$ & $\mathbf{V}$ & $\mathbf{B}$ & $\mathbf{E C}$ & $\mathbf{E h}$ & $\mathbf{p H}$ \\
\hline $\mathrm{Pb}$ & 1 & & & & & & & & \\
\hline $\mathrm{Mg}$ & 0.203547 & 1 & & & & & & & \\
\hline $\mathrm{Fe}$ & 0.023844 & 0.186625 & 1 & & & & & & \\
\hline $\mathrm{Sr}$ & 0.054451 & 0.890862 & 0.207162 & 1 & & & & & \\
\hline $\mathrm{V}$ & 0.464314 & -0.59098 & -0.26617 & -0.62216 & 1 & & & & \\
\hline $\mathrm{B}$ & -0.08217 & -0.28374 & 0.327181 & -0.00609 & 0.123416 & 1 & & & \\
\hline $\mathrm{EC}$ & -0.08137 & 0.205978 & 0.341102 & 0.427316 & -0.00459 & 0.608266 & 1 & & \\
\hline $\mathrm{Eh}$ & 0.278282 & -0.40089 & 0.356247 & -0.57399 & 0.342548 & 0.038067 & 0.34559 & 1 & \\
\hline $\mathrm{pH}$ & -0.04767 & 0.180383 & 0.423703 & 0.064507 & -0.50253 & 0.041902 & 0.33329 & 0.49271 & 1 \\
\hline
\end{tabular}

\section{Results and discussion}

\section{Sources of heavy metals and trace elements in the Oshtorinrn area}

Heavy metals and trace elements in subsurface environments come from natural (weathering of minerals) and anthropogenic (fertilizers, industrial effluent and leakage from service pipes) sources. In the area, industrial and agricultural activities are likely to be the major contamination sources because of the presence of these activities. The main features of the area are 1) rock sources 2) agricultural activities 3) extensive areas of pervious surfaces 4) lack of subsurface drainage systems 5) High traffic rate. Motor vehicles are likely to be the contributor to the pollutants on roads. Pollutants accumulated on road surfaces could be washed by storm as road runoff and finally collected and penetrate into the aquifer that these pollutants include heavy metals and organic chemicals (Ball et al., 1998; Preciado and Li, 2006; Leung and Jiao, 2006; Kiem, 2002; Yannopoulos et al., 2004). In this paper, focus is placed on heavy metals and trace elements. Many studies have investigated the concentrations of heavy metals in stormwater. In Iran, heavy metal contents in road runoff and plants have been studied, some studies measured heavy metals in plants bodies collected in the highways (Saeedi et al., 2009; Maleki and Zarasvand, 2008; Soltani et al., 2015). These data may help to assess the heavy metal compositions of road runoff in Oshtorinan that may be also bring them into the surrounding environments and pollute the groundwater.

6) Wells with diesel engines are probable sources of contamination in the area because in the region, about 88 wells of total 144 wells have been excavated are diesel engines. In addition, a lot of dug wells are also seen that can easily transfer pollution to underground sources and there are not performed the health monitoring, extraction and maintenance.

7) Alloy steel industries, especially in the north entrance that release their effluent on ground surface could be a potential source of contaminants such as heavy and trace metals and threat the environment and groundwater.

Some studies that reported the allowable limits of the levels of some heavy metals in drinking and irrigation water are available elsewhere (Gray, 2008; WHO, 2011). It has been found that the levels of heavy in most groundwater samples are suitable for irrigation and drinking use. However, the levels of $\mathrm{Fe}, \mathrm{Mg}, \mathrm{V}, \mathrm{Sr}$ and $\mathrm{Pb}$ are to higher than the allowable limits. High levels of $\mathrm{Fe}, \mathrm{Mg}$ and $\mathrm{Pb}$ metals could be attributed to the contribution from anthropogenic sources, Industrial and/or domestic activities may in 
the environment of the study area. It could be concluded that the levels of the most elements in the groundwater in Oshtorinan plain are suitable for all purposes. But low relative standard deviation (\%RSD) of heavy metals in different sources (well, spring and qanats) is an indicator of inefficient mixing process of groundwater (Table 2).

\section{Heavy metal and trace element distributions in groundwater in the Oshtorinan area}

The main objective of this study is to evaluate the contaminations of groundwater in terms of heavy metal and trace element. Groundwater samples of natural springs and wells nearby hillsides are comparable to urbanized, industrial and cultivated area and then could be free from any anthropogenic effects. Thus they could be used to evaluate the presence of heavy metal and trace element contaminations in the groundwater.

Tables 3 present the statistical summary of heavy metal and trace element concentrations in groundwater samples collected in dry and wet seasons, respectively. According to analyses, groundwater samples collected in the Zagros slopes and Sanandaj-Sirjan zones had slightly higher DO content than that in the developed areas for both seasons. Most of the groundwater samples in the study area are weakly basic ( $\mathrm{pH}$ ranged from 7 to 8.2) and oxic (DO above $5 \mathrm{mg} / \mathrm{L}$ ) in nature. Since the developed areas are located downhill to the natural slopes, it seems that the distribution of heavy metals and trace elements may be modified by natural processes such as water-rock interactions, but most of the heavy metals and trace elements measured, their average concentrations in the middle parts of basin were higher than that in the natural slopes. This may be the results of natural processes and/or anthropogenic pollution.

According to measurements, some heavy metals, including $\mathrm{Mg}, \mathrm{V}, \mathrm{Fe}, \mathrm{Pb}, \mathrm{Sr}$ and $\mathrm{B}$, in groundwater in the some areas were at significantly higher concentrations than that in the natural slopes. A few sites were even found to have $\mathrm{Pb}$ levels higher than the drinking water guideline value of $10 \mathrm{ppb}$ recommended by WHO (2011). Some of these heavy metals could be derived naturally and suggested that $\mathrm{Mg}$ could be released by incongruent or disproportionate reactions from silicate or oxide minerals and emerge as potential residence-time indicators. Besides, some elements are redox-sensitive and local chemical conditions could affect their availability and mobility in groundwater (Leung and Jiao, 2006; Bourg and Loch, 1995; Hu et al., 2008; Cherry et al., 1984). Statistical analysis indicated that Fe is negatively correlated with DO in both seasons.

Groundwater temperature from granite and granodiorite heights from the east and also from limestone sedimentary rocks at the west to the center show the meaning increasing. In the (Sp) Kartil spring water temperature is $11^{\circ} \mathrm{C}$ while in the (W8) that is close to it shows $18.7^{\circ} \mathrm{C}$ that is questionable. The amount of dissolved oxygen in the surrounding areas from Zagros limestone show higher values than igneous and metamorphic areas can be attributed to more quickly flow in high fractured limestone. Certain groundwater samples from the middle part and cultivated areas (e.g. sites W4, $\mathrm{W} 5$ and $\mathrm{W} 8$ ) contained relatively high $\mathrm{Pb}$ and $\mathrm{Fe}$ concentrations, which may possibly be related to their low, DO contents. This suggests that the concentrations of some heavy metals could be affected by local redox conditions. The concentration of Fe is found to be positively correlated with $\mathrm{pH}$ (R42.3). For most of the other heavy metals, only weak or negative statistical correlations with $\mathrm{pH}$ were observed (Fig $3 a, 3 b$ and $3 e$ ). 
Table 3. Concentration of trace and heavy elements in the Oshtorinan groundwater resoures(dry and wet seasons)

\begin{tabular}{|c|c|c|c|c|c|c|c|c|c|c|c|c|c|c|c|c|c|c|c|c|c|c|c|}
\hline \multirow{16}{*}{ 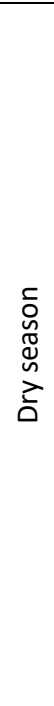 } & & As & B & Ba & $\mathbf{B i}$ & $\mathbf{F e}$ & $\mathbf{L i}$ & $\mathbf{M g}$ & Mo & $\mathbf{N b}$ & $\mathrm{Ni}$ & $\mathbf{P b}$ & $\mathbf{R b}$ & Sc & Se & Sn & $\mathrm{Sr}$ & Ta & Te & Th & $\mathbf{U}$ & $\mathbf{V}$ & $\mathbf{W}$ \\
\hline & Q1 & 4.8 & 69 & 31.8 & 9.2 & 0.255 & 16.4 & 30.5 & 6.1 & 4.9 & 12 & 4.5 & 19.3 & 14 & 2.4 & 5.7 & 0.86 & 4.5 & 8.7 & 11.4 & $<1$ & 95.8 & 30 \\
\hline & Q2 & 3.5 & 62 & 32.7 & 3.7 & 0.243 & 21 & 36.3 & 6 & 2.8 & 13 & 4.1 & 12 & 14 & 0.7 & 3.3 & 0.89 & 3.3 & 3 & 2.9 & 2.3 & 85.8 & 23.2 \\
\hline & Q3 & 3.5 & 166 & 25.7 & 2.7 & 0.275 & 20.7 & 19.5 & 4.9 & 2.3 & 12 & 4.7 & 9.1 & 14 & 0.5 & 2.3 & 0.73 & 2.5 & 1.7 & 1.4 & 3.1 & 104.9 & 21.9 \\
\hline & Q4 & 3.4 & 150 & 9.9 & 2.3 & 0.165 & 8 & 6.9 & 2.2 & 1.9 & 11 & 5.1 & 7.7 & 16 & 0.7 & 3 & 0.27 & 3.2 & 1.1 & 0.9 & 1.1 & 126.5 & 20.6 \\
\hline & Q5 & 3.2 & 138 & 29.6 & 2.3 & 0.219 & 13.2 & 19.7 & 5.2 & 2 & 15 & 6.2 & 6.3 & 18 & 1.1 & 2 & 0.72 & 2.1 & 1 & 0.5 & 5.3 & 133.8 & 21.2 \\
\hline & W1 & 3.3 & 62 & 35.5 & 2 & 0.242 & 12.3 & 18.3 & 3.9 & 1.4 & 13 & 5.6 & 4.7 & 22 & 1.3 & 2.5 & 0.67 & 1.7 & 0.7 & 0.3 & 4.5 & 113.3 & 19 \\
\hline & W2 & 3.7 & 64 & 24.8 & 1.9 & 0.293 & 9.6 & 14.4 & 3.3 & 1.6 & 11 & 4.5 & 5.5 & 22 & 1.1 & 1.8 & 0.47 & 1.6 & 0.6 & 0.1 & 5.2 & 123.9 & 20 \\
\hline & W3 & 4.8 & 49 & 26.1 & 1.8 & 0.218 & 15.1 & 8.5 & 4.6 & 1.3 & 18 & 5.2 & 5.3 & 16 & 1.2 & 2.2 & 0.35 & 1.5 & 0.5 & 0.1 & 5.1 & 142.9 & 27 \\
\hline & W5 & 4.3 & 233 & 32.9 & 1.8 & 0.312 & 26.5 & 15.5 & 4.6 & 1.1 & 11 & 25.9 & 4.9 & 17 & 1.1 & 2.3 & 0.63 & 1.3 & 0.4 & $<0.1$ & 3.6 & 150.7 & 19.6 \\
\hline & W6 & 3.9 & 381 & 47.6 & 1.7 & 0.284 & 20 & 9.6 & 4.6 & 1.1 & 11 & 4.3 & 4.6 & 17 & 1.1 & 2.4 & 0.45 & 1.6 & 0.3 & $<0.1$ & 6.6 & 151 & 20.5 \\
\hline & W7 & 5.1 & 394 & 17.7 & 1.7 & 0.241 & 12.4 & 12.4 & 4.8 & 1.2 & 13 & 4.5 & 3.5 & 22 & 1.7 & 3.1 & 0.59 & 2.4 & 0.3 & $<0.1$ & 1.4 & 171.4 & 19 \\
\hline & Q6 & 2.9 & 5 & 35.8 & 1.7 & 0.119 & 15.1 & 13 & 3.3 & 1 & 15 & 8.3 & 3.4 & 28 & 0.9 & 2.3 & 0.52 & 1.1 & 0.3 & $<0.1$ & $<1$ & 162.7 & 19.3 \\
\hline & Q7 & 3.1 & 41 & 62.7 & 1.7 & 0.069 & 10.8 & 23.4 & 1.9 & 0.9 & 20 & 8.2 & 3.7 & 31 & 1 & 2 & 0.7 & 1 & 0.3 & $<0.1$ & 1.1 & 166.1 & 18.8 \\
\hline & W8 & 3 & 89 & 134.4 & 1.7 & 0.314 & 18.9 & 18.6 & 3.1 & 0.8 & 14 & 17.3 & 4.3 & 30 & 1 & 2.4 & 0.5 & 1.4 & 0.3 & $<0.1$ & $<1$ & 186.6 & 18.2 \\
\hline & $\mathrm{S} 1$ & 3.2 & $<1$ & 3.2 & 1.6 & 0.265 & 3 & 7.4 & 1.2 & 0.9 & 15 & 4.9 & 2.9 & 34 & 1.8 & 2.2 & 0.12 & 1.2 & 0.2 & $<0.1$ & $<1$ & 195.5 & 18.1 \\
\hline \multirow{15}{*}{ 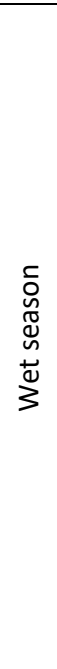 } & Q1 & 3.7 & 71 & 30.3 & 8.6 & 0.33 & 15.5 & 27.3 & 5.7 & 4.7 & 11 & 47.1 & 16.6 & 12 & 2.4 & 5.2 & 0.93 & 4.2 & 7.8 & 9.9 & $<1$ & 86.5 & 25.2 \\
\hline & Q3 & 2.3 & & 21.7 & 1.9 & 0.244 & 14 & 28.5 & 3.8 & 2 & 15 & 29.5 & 6.1 & 14 & 0.3 & 1.6 & 0.73 & 1.4 & 1.1 & 0.8 & 2.4 & 96.8 & 18.7 \\
\hline & $\mathrm{Q} 4$ & 3.9 & 152 & 12.3 & 1.7 & 0.21 & 11 & 28.5 & 2.2 & 2.2 & 14 & 25.21 & 7.9 & 14 & 0.8 & 3 & 0.68 & 3.2 & 1.3 & 1.1 & 0.9 & 121.6 & 19.3 \\
\hline & Q5 & 3 & 144 & 27.7 & 2.1 & 0.2 & 17 & 28.5 & 5.1 & 2.1 & 15 & 27.8 & 5.9 & 17 & 0.8 & 1.7 & 0.72 & 1.9 & 0.8 & 0.4 & 4.6 & 135.9 & 21.3 \\
\hline & W1 & 3.3 & 53 & 30.1 & 2.2 & 0.351 & 13 & 17.7 & 4.2 & 1.3 & 13 & 27.3 & 4.7 & 18 & 1.1 & 2.2 & 0.67 & 1.7 & 0.8 & 0.4 & 4.1 & 108.5 & 18 \\
\hline & W2 & 3.5 & 61 & 25.6 & 2.8 & 0.351 & 17 & 14 & 3.8 & 1.9 & 14 & 32 & 5.8 & 18 & 0.9 & 2.1 & 0.47 & 1.1 & 0.9 & 0.3 & 5 & 121.1 & 19 \\
\hline & W3 & 5.1 & 49 & 22.6 & 1.6 & 0.3 & 15 & 6.8 & 4.6 & 1.2 & 17 & 28 & 4.7 & 14 & 0.8 & 2 & 0.35 & 1.2 & 0.6 & 0.2 & 4.9 & 138.6 & 25 \\
\hline & W4 & 3.3 & 222 & 27.3 & 1.6 & 0.22 & 16 & 6.647 & 5.5 & 0.9 & 14 & 25.9 & 3.8 & 12 & 1.4 & 1.6 & 0.32 & 0.9 & 0.3 & 0.1 & 6.3 & 138.6 & 18.8 \\
\hline & W5 & 4 & 257 & 33.9 & 1.7 & 0.362 & 27 & 14.32 & 4.2 & 1 & 10 & 38.6 & 4.6 & 15 & 1.1 & 2.1 & 0.58 & 1.4 & 0.5 & $<0.1$ & 4.1 & 143.5 & 18.2 \\
\hline & W6 & 4.7 & 387 & 52.2 & 2.3 & 0.29 & 35 & 33.37 & 4.5 & 1.5 & 13 & 29.2 & 4.6 & 16 & 1.2 & 2.2 & 0.45 & 1.9 & 0.5 & $<0.1$ & 6.8 & 142.7 & 21.7 \\
\hline & W7 & 6.1 & 387 & 21.6 & 2.3 & 0.35 & 35 & 33.37 & 5.1 & 1.6 & 14 & 25.2 & 3.7 & 18 & 1.4 & 3.3 & 0.8 & 2.2 & 0.4 & $<0.1$ & 0.9 & 159.6 & 19.6 \\
\hline & Q6 & 2.9 & 4 & 34.2 & 1.5 & 0.98 & 8 & 12.21 & 2.9 & 1.4 & 11 & 31.3 & 3.1 & 21 & $\begin{array}{l}0.9 \\
\end{array}$ & 1.8 & 0.38 & 0.8 & 0.2 & $<0.1$ & $<1$ & 149.6 & 21.2 \\
\hline & Q7 & 4.2 & 30 & 66.4 & 1.9 & 0.07 & 18 & 23.27 & 2.7 & 0.6 & 22 & 33.4 & 3.8 & 22 & 1.2 & 2.3 & 0.74 & 0.8 & 0.6 & $<0.1$ & 1.2 & 168.5 & 20.3 \\
\hline & W8 & 1.9 & 103 & 121.9 & 1.4 & 0.21 & 13 & 18.29 & 2.3 & 0.6 & 9 & 45.2 & 3.8 & 19 & 0.7 & 1.9 & 0.48 & 1 & 0.2 & $<0.1$ & $<1$ & 177.3 & 15.7 \\
\hline & $\mathrm{S} 1$ & 2.2 & 1 & 2.1 & 1.4 & 0.246 & 1 & 8.821 & 0.8 & 0.6 & 11 & 41.9 & 2.4 & 26 & 1.6 & 2 & 0.09 & 0.9 & 0.1 & $<0.1$ & $<1$ & 182.3 & 16.8 \\
\hline
\end{tabular}



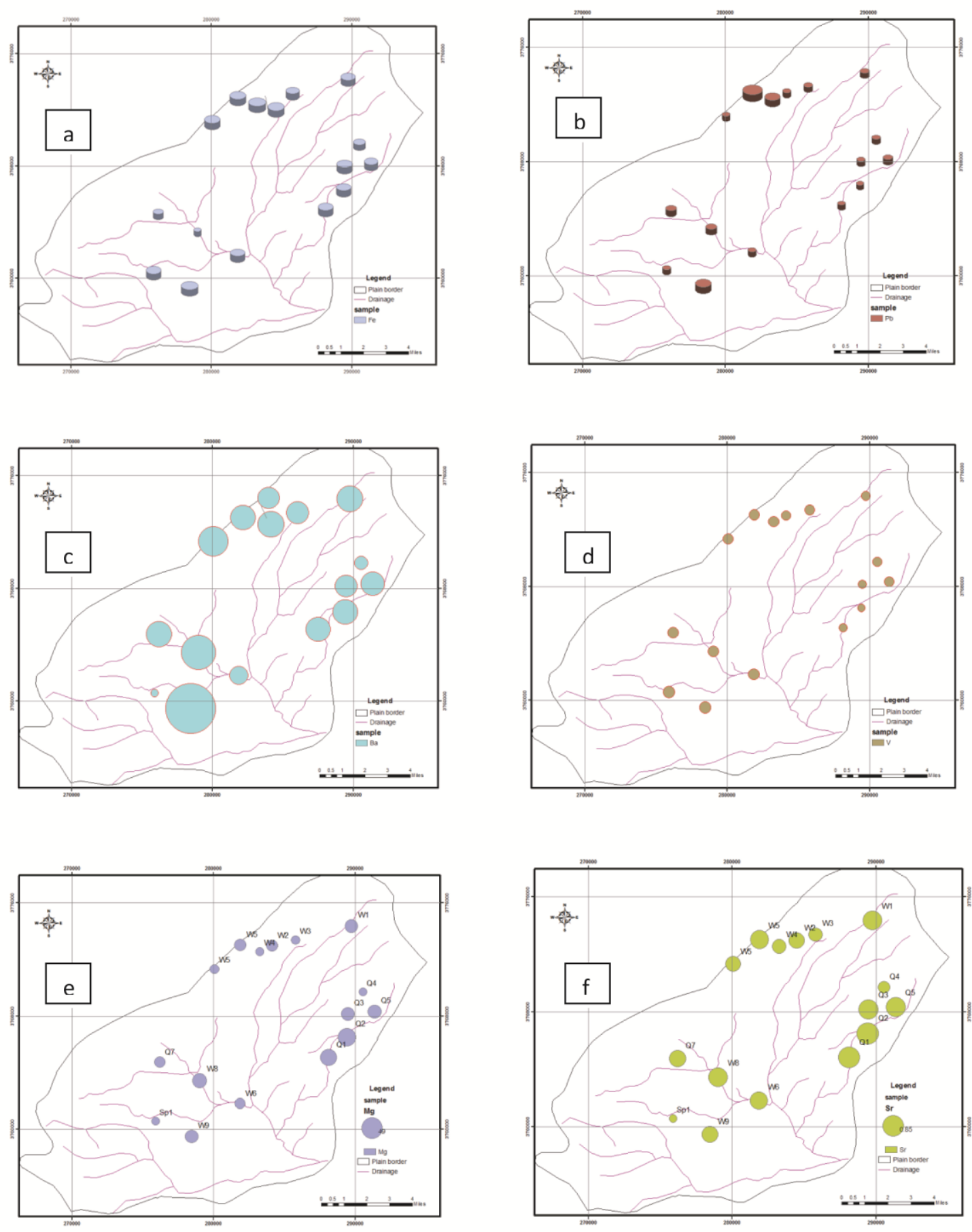

Figure 3. a, b, $\boldsymbol{c}, \boldsymbol{d}, \boldsymbol{e}, \boldsymbol{f}$. show heavy metal ( $\mathrm{Fe}, \mathrm{Pb}, \mathrm{Ba}, \mathrm{V}, \mathrm{Mg}$ and $\mathrm{Sr}$ ) distribution in the Oshtorinan groundwater

However, natural processes alone may not be able to account for the observed concentrations. Besides, $\mathrm{Fe}$ and $\mathrm{Pb}$ could also be derived from steel corrosion. These heavy metals are used as additives on steel production. An alloy steel factory is located at the upstream side of groundwater direction and inlet of the Oshtorinan that release its wastewater into the aquifer without any quality control and pollution supervision. Erosion and weathering of and Sanandaj-Sirjan rocks in the area may result in 
increasing of dissolved $\mathrm{Fe}$ in the groundwater. Fig. $3 a$ and $3 b$ show the spatial distribution of $\mathrm{Fe}$ and $\mathrm{Pb}$ using interpolation method in GIS environment. Lead contamination of the ground water may be the result of entry from industrial effluents, old plumbing, household sewages, agricultural run-off containing phosphate fertilizers and human and animal excreta (Ritter, 2002; Sirajudeen and Abdul Jameel, 2006; Falta, 2004; Savci, 2012). In addition to the symptoms found in acute lead exposure, symptoms of chronic lead exposure could be allergies, arthritis, hyperactivity, mood swings, nausea, and numbness, lack of concentration, seizures and weight loss. The sample W8 has maximum concentration in the southeastern of the plains and adjacent military barracks. According to measurments, three samples are above the maximum permissible limit.

Magnesium, except in samplesQ1, Q2 shows the allowed values that their concentration were 30.5 and 36.3 ppm respectively, which relate to Dareh Garm and Dareh Gorg road Qanats. Weathering of hornfels and schist of Sanandaj-Sirjan zone can cause magnesium washed down into the groundwater. Concentration of $\mathrm{Ba}$ ranges from 3 to $132 \mathrm{ppb}$. The lowest concentrations of $\mathrm{Ba}$ are noticed in the southwest $(\mathrm{Sp})$ whereas, the highest concentration is recorded at its neighbor (W8) (Fig. 3c). Ba values were below the MPL for drinking and irrigation water. The differences for some elements between the Kartil spring (Sp) and the nearby water sources could be a good knowledge of hydrogeological conditions and hydraulic connection with limestone formations and recharge from them. Sb was not detectable Except for sample Q1 with concentration 5.1 $\mathrm{ppb}$, which is influenced by weathering of schist and hornfels.

The concentration of $\mathrm{V}$ varies between 79 to $196 \mathrm{ppb}$ that highest value appears in the southwest. The concentration of vanadium in drinking water depends significantly on geographical location and Shawn in Fig 3d. Groundwater samples in the samples near Sanandaj-Sirjan zone contained Sr concentrations ranging from 120 to $890 \mathrm{ppb}$ with an average of $578 \mathrm{ppb}$, which is significantly higher than near the Zagros resulted from natural sources such as the weathering of plagioclase feldspar. Therefore, presence of Granite and Granodiorite rocks in east part can justify the high level of Sr.

\section{Industrial and agricultural activities effect on groundwater quality}

Boron is a good indicator of the presence of sewage (Barber et al., 1988; Pitt et al., 2000; Verstraeten et al., 2005; Leung and Jiao, 2006). In the middle of plain, the concentration of boron in groundwater ranged from 1 to $394 \mathrm{ppb}$ with average of 134.07 ppb. In the Zagros and Sanandaj-Sirjan slopes, it ranged from 5 to $69 \mathrm{ppb}$ with an average of $41 \mathrm{ppb}$. The average boron concentration in the center was about five times higher than that in the natural slopes, indicating that groundwater in the developed areas was likely to be contaminated by the leakage from sewage. Boron is also found to be low positively correlated with Fe, suggesting that boron and iron may be derived from the same source, possibly from sewage. Spatial distribution map of boron (Fig 3e) depicts that maximum concentration of boron at Central, and western part of Oshtorinan basin. Boron concentration indicates that the samples fall within the permissible limit set by WHO.

\section{Seasonal differences of heavy metal concentrations in the study area}

The samples collected both in wet and dry seasons are compared to examine the seasonal effects on groundwater heavy metal and trace element contents. A total of 
16sample sites in the basin are selected for comparison. According to Table 3, both the Zagros and Sanandaj-Sirjan zones, groundwater samples collected in the wet season had slightly lower $\mathrm{pH}$ and higher DO contents than dry season. The seasonal comparisons of trace element contents in the Oshtorinan plain are presented in Table 4 for both the natural slopes and the developed areas, the average concentrations of most of the heavy metals and trace elements are higher in wet season than in dry season. It is suggested by (Vaze and Chiew, 2003) that the concentrations of heavy metals in road runoff are particularly high when short duration; intense summer storms follow a long dry period during which pollutants have accumulated on the road surface. However, as discussed, the impacts of leakage from stormwater drains on the heavy metals and trace elements in groundwater appear to be insignificant. Another explanation is that more heavy metals and trace elements could be leached out in wet season because of the generally higher water table during the season. In addition, more chemicals may be washed out directly from the vadose zone by infiltrated rainwater during the wet season. Higher concentrations were obtained in the wet season than in dry season, and in hand dug wells than in boreholes.

Table 4. Seasonal variation of trace element concentration in Oshtorinan Groundwater Resources

\begin{tabular}{|c|c|c|c|c|c|c|c|c|c|c|}
\hline \multicolumn{6}{|c|}{ Dry Season } & \multicolumn{5}{|c|}{ Wet Season } \\
\hline Element(ppb) & Min & Mean & Max & SD & $\mathrm{CV}$ & Min & Mean & Max & SD & $\mathrm{CV}$ \\
\hline As & 2.9 & 3.831 & 5.6 & 0.834 & 0.689 & 1.9 & 3.562 & 6.1 & 1.1068 & 0.8453125 \\
\hline $\mathrm{Ba}$ & 3.2 & 36.668 & 134.4 & 29.466 & 16.836 & 2.1 & 35.062 & 121.9 & 27.331 & 16.9140625 \\
\hline $\mathrm{Zn}$ & 7.5 & 12.53333 & 20.1 & 6.671082 & 5.044444 & 6.2 & 12 & 18.8 & 6.359 & 4.533333333 \\
\hline $\mathrm{Sr}$ & 0.12 & 0.5525 & 0.89 & 0.211865 & 0.17125 & 0.09 & 0.578 & 0.93 & 0.228 & 0.18890625 \\
\hline $\mathrm{Se}$ & 0.5 & 1.23125 & 2.4 & 0.519896 & 0.392969 & 0.3 & 1.0687 & 2.4 & 0.492 & 0.35625 \\
\hline $\mathrm{Li}$ & 3 & 15.8625 & 30.8 & 7.013119 & 5.407813 & 1 & 16.968 & 35 & 8.866 & 6.1484375 \\
\hline $\mathrm{V}$ & 85.8 & 141.6 & 195.5 & 31.80082 & 25.9 & 79.3 & 134.4 & 182.3 & 30.666 & 24.075 \\
\hline $\mathrm{Rb}$ & 2.9 & 6.4 & 19.3 & 4.163012 & 2.8125 & 2.4 & 5.675 & 16.6 & 3.403 & 2.19375 \\
\hline Mo & 1.2 & 4.1125 & 6.1 & 1.502831 & 1.235938 & 0.8 & 3.925 & 5.7 & 1.401 & 1.121875 \\
\hline $\mathrm{Pb}$ & 30.6 & 43.725 & 62.9 & 9.708587 & 8.01875 & 25.2 & 32.438 & 47.1 & 7.037 & 5.501171875 \\
\hline $\operatorname{Mg}(\mathrm{ppm})$ & 6.9 & 16.3375 & 36.3 & 8.430016 & 6.492188 & 5.6 & 15.175 & 26.6 & 5.368 & 4.1125 \\
\hline $\mathrm{Ni}$ & 11 & 13.8125 & 20 & 2.713393 & 2.164063 & 9 & 13.315 & 22 & 3.198 & 2.3125 \\
\hline $\mathrm{Sn}$ & 0.12 & 0.5525 & 0.89 & 0.211865 & 0.17125 & 1.6 & 2.381 & 5.2 & 0.911 & 0.634375 \\
\hline $\mathrm{Ta}$ & 1 & 1.9875 & 4.5 & 0.970137 & 0.759375 & 0.8 & 1.718 & 4.2 & 0.981 & 0.7484375 \\
\hline $\mathrm{Te}$ & 0.2 & 1.2375 & 8.7 & 2.116562 & 1.210938 & 0.1 & 1.175 & 7.8 & 1.872 & 1.034375 \\
\hline $\mathrm{U}$ & 1.1 & 4.008333 & 8.8 & 2.37083 & 1.908333 & 0.9 & 3.575 & 6.8 & 2.090 & 1.795833333 \\
\hline $\mathrm{Bi}$ & 1.6 & 2.49375 & 9.2 & 1.865643 & 1.014844 & 1.4 & 2.406 & 8.6 & 1.742 & 0.96015625 \\
\hline $\mathrm{Nb}$ & 0.8 & 1.6625 & 4.9 & 1.026889 & 0.698438 & 0.6 & 1.6375 & 4.7 & 1.019 & 0.709375 \\
\hline $\mathrm{Sc}$ & 14 & 20.5625 & 34 & 6.762334 & 5.632813 & 12 & 16.8125 & 26 & 3.885 & 3.0625 \\
\hline Th & 0.1 & 1.977 & 11.4 & 3.645 & 2.298 & 0.1 & 1.666 & 9.9 & 3.133 & 1.859259259 \\
\hline W & 18.1 & 21.112 & 30 & 3.245 & 2.253 & 15.7 & 19.893 & 25.2 & 2.568 & 1.9171875 \\
\hline $\mathrm{Fe}$ & 0.069 & 0.27 & 0.4 & 0.0905 & 0.07 & 0.07 & 0.313 & 0.98 & 0.193 & 0.10546875 \\
\hline B & 1 & 134.0625 & 387 & 122.6390198 & 95.8203125 & 5 & 139.733 & 394 & 118.581 & 90.48 \\
\hline
\end{tabular}




\section{Conclusion}

The current study reports for the first time the investigation of the levels of heavy metals and trace element concentrations in groundwater samples in Oshtorinan basin, Iran. From this investigation, the following results can be made. The levels of heavy metals under study in water used for drinking purpose are below the maximum allowable limits recommended by WHO except for $\mathrm{Fe}, \mathrm{Mg}, \mathrm{Pb}, \mathrm{Sr}$, and $\mathrm{V}$. This shows that the vadose zone could effectively remove many of the heavy metals and thus protect the underlying groundwater from contaminations. The study revealed that the groundwater in Oshtorinan affected by heavy metals enrichment by anthropogenic sources or may also be derived from remobilization from natural weathering and changes in local redox conditions. Thus, in time, geogenic processes together with anthropogenic activity will lead to elevated heavy metal accumulation in the study area.

The levels of $\mathrm{Pb}, \mathrm{B}$ and $\mathrm{Fe}$ in groundwater in the area understudy increase from east and west to center. To some extent, higher levels of $\mathrm{Sr}, \mathrm{V}$ and $\mathrm{Mg}$ were recorded in the Eastern part in the area under study. It is found that elevated levels of the strontium concentration ( $\mathrm{Sr}$ ) in groundwater were considered to be mainly the result of natural processes such as the weathering of minerals such as feldspars in granites and Granodiorites. Moreover, igneous, metamorphic and carbonate rocks in the one hand and human activities like mining, the other hand, have had a significant effect on the concentrations of these elements in the groundwater, as seen in the analysis of W3.

Higher concentrations of elements in the W1 than other near samples originated from the weathering of Hornfelses and Schists that clearly visible in the field survey, as a result of surface weathering and erosion and dissolution of the elements in minerals.

The proposed studies would be crucial for further Geochemistry studies in the Oshtorinan area and helps to identify the significant parameters of getting better information about source of pollution in the areas with a similar geology bounded by different structures. The spatial and seasonal variations in most of the investigated variables suggest point source contamination in wells and dug wells.

Acknowledgements. This study was supported by the Department of Geology, Shahid Chamran University of Ahvaz-Iran. The authors gratefully acknowledge the Lorestan Regional Water Authority for accessing to the existing data, field operations and data collection; also wish to thank Dr.Jalal Hasan for water chemical analyses.

\section{REFERENCES}

[1] Adeyemi, O., Oloyede, O., Oladihi, A. (2007): Physicochemical and microbial characteristics of leachate-contaminated groundwater. - Asian J. Biochem 2: 343-348.

[2] Asarab (2012). Hydrochemical study of Boroujerd basin. - Iran Power Ministry.

[3] Ball, J., Jenks, R., Aubourg, D. (1998): An assessment of the availability of pollutant constituents on road surfaces. - Science of the Total Environment 209: 243-254.

[4] Barber, L. B., Thurman, E. M., Schroeder, M. P., Leblanc, D. R. (1988): Long-term fate of organic micropollutants in sewage-contaminated groundwater.- Environmental science \& technology 22: 205-211.

[5] Botte, S. E., Feije, R. H., Marchovecchio, J. E. (2007): Dissolved heavy metal (Cd, Pb, $\mathrm{Cr}, \mathrm{Ni}$ ) concentrations in surface water and porewater from Bahía Blanca estuary tidal flats. - Bulletin of environmental contamination and toxicology 79: 415-421. 
[6] Bourg, A., Loch, J. G. (1995): Mobilization of heavy metals as affected by pH and redox conditions. - Biogeodynamics of pollutants in soils and sediments. Springer

[7] Cherry, J. A., Gillham, R. W., Barker, J. F. (1984): Contaminants in groundwater: Chemical processes. - Groundwater contamination, pp. 46-64.

[8] Dawson, E., Macklin, M. (1998): Speciation of heavy metals on suspended sediment under high flow conditions in the River Aire, West Yorkshire, UK. - Hydrological Processes 12: 1483-1494.

[9] Eaton, A., Clesceri, L. S., Greenberg, A. (1995): APHA, AWWA, WEF, Standard methods for the examination of water and wastewater. 19th edn, Washington, DC, USA.

[10] Falta, R. W. (2004): The potential for ground water contamination by the gasoline lead scavengers ethylene dibromide and 1, 2-Dichloroethane. - Groundwater Monitoring \& Remediation 24: 76-87.

[11] Gray, N. F. (2008): Drinking water quality: problems and solutions.- Cambridge University Press.

[12] Greenwood, N. N. Earnshaw, A. (2012): Chemistry of the Elements. - Elsevier.

[13] Hajmollaali, A., Hosseini, M., Farhadian, M. B., Sedaghat, E. (1991): Geological map of Borujerd quadrangle 5757, 1:100000. - Geological Survey of Iran.

[14] Hassanzadeh, R., Abbasnejad, A., Hamzeh, M. (2011): Assessment of groundwater pollution in Kerman urban areas.- Journal of Environmental Studies 56: 101-10.

[15] Hu, Q., Zavarin, M. \& Rose, T.(2008): Effect of reducing groundwater on the retardation of redox-sensitive radionuclides.- Geochemical transactions 9: 1.

[16] Khalaji, A. A., Esmaeily, D., Valizadeh, M., Rahimpour-Bonab, H. (2007): Petrology and geochemistry of the granitoid complex of Boroujerd, Sanandaj-Sirjan Zone, Western Iran. - Journal of Asian Earth Sciences 29: 859-877.

[17] Kiem, S. (2002): Heavy metal pollution of water from road runoff. Bachelor degree thesis, School of Engineering, James Cooks University.

[18] Leung, C.M., JIAO, J. J. (2006): Heavy metal and trace element distributions in groundwater in natural slopes and highly urbanized spaces in Mid-Levels area, Hong Kong. - Water Research 40: 753-767.

[19] Maleki, A., Zarasvand, M. A. (2008): Heavy metals in selected edible vegetables and estimation of their daily intake in Sanandaj, Iran.

[20] Marcovecchio, J. E., Botte, S. E., Freije, R. H. (2007): Heavy metals, major metals, trace elements. - Handbook of water analysis 2: 275-311.

[21] Marengo, E., Gennaro, M. C., Robotti, E., Rossanigo, P., Rinaudo, C., Rozgastaldi, M. (2006): Investigation of anthropic effects connected with metal ions concentration, organic matter and grain size in Bormida river sediments. - Analytica Chimica Acta 560: 172-183.

[22] Mohajjel, M., Fergusson, C., Sahandi, M. (2003): Cretaceous-Tertiary convergence and continental collision, Sanandaj-Sirjan zone, western Iran. - Journal of Asian Earth Sciences 21: 397-412.

[23] Momodu, M., Anyakora, C. (2010): Heavy metal contamination of groundwater: the Surulere case study. - Res J Environ Earth Sci 2: 39-43.

[24] Murena, F. (2004): Measuring air quality over large urban areas: development and application of an air pollution index at the urban area of Naples. - Atmospheric Environment 38: 6195-6202.

[25] Pirsaheb, M., Khosravi, T., Sharafi, K., Babajani, L., Rezaei, M. (2013): Measurement of Heavy Metals Concentration in Drinking Water from Source to Consumption Site in Kermanshah-Iran. - World Applied Sciences Journal 21: 416-423.

[26] Pitt, R., Lalor, M., Harper, J., Nix, C.(2000): Potential new tools for the use of tracers to indicate sources of contaminants to storm drainage systems. - U. S. Environmental Protection Agency, National Conference on Tools for Urban Water Resource Management and Protection Proceedings 97-109. 
[27] Preciado, H. F., Li, L. Y. (2006): Evaluation of metal loadings and bioavailability in air, water and soil along two highways of British Columbia, Canada. - Water, Air, and Soil Pollution 172: 81-108.

[28] Ritter, K. S., Silbey, P., Hall,K., Keen,P., Mattu, G., Linton, B. (2002): Sources, pathways, and relative risks of contaminants in surface water and groundwater: a perspective prepared for the Walkerton inquiry. - Journal of Toxicology and Environmental Health Part A, 65: 1-142.

[29] Saeedi, M., Hosseinzadeh, M., Jamshidi, A., Pajooheshfar, S. (2009): Assessment of heavy metals contamination and leaching characteristics in highway side soils, Iran. Environmental monitoring and assessment 151: 231-241.

[30] Savci, S. (2012). An agricultural pollutant: chemical fertilizer. - International Journal of Environmental Science and Development 3: 73.

[31] Sirajudeen, J., Abdul Jameel, A. (2006): Studies on heavy metal pollution of Groundwater sources between Tamilnadu and Pondicherry India. - J. Ecotoxicol. Environ. Monit 16: 443-446.

[32] Soltani, N., Keshavarzi, B., Moore, F., Tavakol, T., Lahijanzadeh, A. R., Jaafarzadeh, N., Kermani, M. (2015): Ecological and human health hazards of heavy metals and polycyclic aromatic hydrocarbons (PAHs) in road dust of Isfahan metropolis, Iran. Science of the Total Environment 505: 712-723.

[33] Thibodeaux, L. J. (1996): Environmental chemodynamics: Movement of chemicals in air, water, and soil. - John Wiley \& Sons.

[34] Vaze, J., Chiew, F. H. (2003): Study of pollutant washoff from small impervious experimental plots. - Water Resources Research, 39.

[35] Verstraeten, I., Fetterman, G., Meyer, M., Bullen, T., Sebree, S. (2005): Use of tracers and isotopes to evaluate vulnerability of water in domestic wells to septic waste. Groundwater Monitoring \& Remediation 25: 107-117.

[36] Vodela, J., Renden, J., Lenz, S., Mcelhenney, W., Kemppainen, B. (1997): Drinking water contaminants (arsenic, cadmium, lead, benzene, and trichloroethylene). 1. Interaction of contaminants with nutritional status on general performance and immune function in broiler chickens. - Poultry Science 76: 1474-1492.

[37] Wauchope, R. (1978): The pesticide content of surface water draining from agricultural fields - a review. - Journal of environmental quality 7: 459-472.

[38] WHO, G. (2011). Guidelines for drinking-water quality. - World Health Organization 216: 303-4.

[39] Yannopoulos, S., Basbas, S., Ansrianos, T., Rizos, C. (2004): Receiving waters pollution investigation due to the interurban roads stormwater runoff. - Proceedings from the International Conference on Protection and Restoration of the Environment VII. 